\title{
COLLAGEN CONTENT OF RABBIT SCIATIC NERVE DURING WALLERIAN DEGENERATION
}

\author{
BY \\ M. ABERCROMBIE and M. L. JOHNSON \\ (Department of Zoology, University of Birmingham) \\ (RECEIVED 23RD July, 1946)
}

DuRING Wallerian degeneration the peripheral stump of a severed nerve increases its endoneurial collagen content (Holmes and Young, 1942). This collagenization is greatest in the neighbourhood of the injury which originally divided the nerve; but it is also evident throughout the length of the peripheral stump. We have attempted in the present investigation to obtain a quantitative measure of collagen formation in the non-traumatized part of the peripheral stump, with the object of correlating its progress with the other proliferative activities so conveniently studied quantitatively in degenerating peripheral nerve (Abercrombie and Johnson, 1946). An understanding of the process of collagenization is also desirable from the practical standpoint of neurosurgery. During prolonged degeneration in the absence of reinnervation the Schwann tubes shrink in diameter, and Holmes and Young (1942) and Sanders and Young (1944) found that such collapsed tubes fail to expand again to their normal size when eventually reinnervated. Collagen formation around the shrunken tubes is probably largely responsible for this failure to re-expand, which seems to be one of the hindrances to return of adequate function after prolonged delay in suture. Since histological sections cannot provide the quantitative data we need, we have applied the chemical method of collagen estimation devised by Lowry, Gilligan, and Katersky (1941).

\section{Material and Method}

Throughout the investigation we used the sciatic nerve of adult rabbits of known age, mostly six to eight months old; a few up to eighteen months old. An analysis of the influence of age showed that although the undegenerated nerves of old rabbits (more than twelve months) were significantly heavier than those of younger rabbits, their absolute collagen averaged almost the same as those of younger rabbits, and so did the amount of collagen they formed during degeneration. When collagen content of nerve is expressed per $100 \mathrm{mg}$. wet weight of the nerve before degeneration, which is the method of expression used in this paper, old rabbits have, therefore, unusually low values. We were unable, however, to establish the statistical significance of this difference between old and young rabbits, owing to the small numbers of old rabbits involved. We do not consider that age differences bias our results significantly, since they were fairly well distributed amongst our material.

At an initial aseptic operation under nembutal and ether anæsthesia the sciatic nerve of one side was cut $1.5 \mathrm{~cm}$. below the third trochanter with sharp scissors. The central stump, except in nerves degenerated only 25 days, was then sutured to the skin to prevent reinnervation. At autopsy, 25, 50, 100 , or 200 days later, the whole peripheral stump of the sciatic nerve in the thigh, except the halfcentimetre nearrest the cut, together with $3 \mathrm{~cm}$. of the main branch in the shank of peroneal and of tibial nerves, were removed for collagen estimation. The undegenerated nerve of the other leg was cut $2 \mathrm{~cm}$. below the third trochanter, and an exactly corresponding extent removed for parallel estimation; in two experiments both nerves were degenerated different periods, 100 and 260 days. The nerves were stripped from their epineurium, so that the material tested consisted of everything within the perineurium of each funiculus, and included most of the perineurium itself. The wet weight of the material from each side of the rabbit was taken and the extraction process started, each sciatic nerve being estimated separately. The proximal half-centimetre of peripheral stump, which was not used for collagen estimation, was fixed and stained by Bodian's method for axons. We were successful in avoiding serious reinnervation in all experiments.

We determined collagen content by the method of Lowry, Gilligan, and Katersky (1941), slightly modified. For the rather small quantities of tissue involved (50-130 mg. wet weight), and in view of the apparatus at our disposal, we found it better to abandon the dry weight method of estimation proposed by these authors, and to substitute a micro-Kjeldahl estimation of nitrogen. In experiments in which both methods of estimation were applied to the same nerves, using precautions in getting the dry weights which could not be employed 
as a routine, good agreement between the two methods resulted. The mean collagen content of eight undegenerated nerves was 2.8 and $2.6 \mathrm{mg}$. by dry weight and nitrogen estimation respectively; and of nine 200-day degenerated nerves it was 6.1 and $5.9 \mathrm{mg}$. respectively. With care the technique can be used on very small amounts of tissue, and we have estimated the collagen in only $2-5 \mathrm{mg}$. of nerve, though not with entire satisfaction. In outline the estimation, which was throughout standardized as highly as possible, involved the following steps: $(a)$ mincing with scissors, and pounding in pestle and mortar with a trace of sand; $(b)$ extraction with several changes of $\mathrm{M} / 10 \mathrm{NaOH}$ for 24 or 48 hours (the supernatant contained most of the nerve protein, and we usually estimated its nitrogen content, referred to as " $\mathrm{NaOH}$-soluble $\mathrm{N}$ "); (c) approximate neutralization with $\mathrm{M} / 10 \mathrm{HCl}$, using bromothymol blue as indicator; $(d)$ extraction with alcohol and ether; $(e)$ addition of distilled water and autoclaving at $30 \mathrm{lb}$. per sq. in. for five hours; $(f)$ estimation of nitrogen in the supernatant, which contained the collagen converted to gelatin, ("collagen $\mathrm{N}$ ") and in most experiments also that in the insoluble residue (" residue $\mathrm{N}$ ").

The undegenerated control nerves gave throughout the series of experiments a useful check on the constancy of the method. There was no perceptible systematic change in the values obtained from them. In stage $(b)$ we used two different durations of $\mathrm{NaOH}$ extraction, 24 hours and 48 hours, to obtain some evidence as to whether this treatment appreciably affected the estimation of collagen nitrogen. We found that, at each time of degeneration, collagen $\mathbf{N}$ as percentage of total $\mathbf{N}$ was less with long extraction than with short. In the undegenerated nerves the decrease represented a loss of only 2 per cent. of the absolute amount of collagen after short extraction, and was statistically quite insignificant $(P>0 \cdot 1)$. In the degenerated nerves the loss averaged 10 per cent., and when examined by analysis of variance proved to be significant $(\mathrm{P}<0.01)$. The $\mathrm{NaOH}$-soluble $\mathrm{N}$ increased with long extraction in all groups; in the undegenerated nerves the gain was from the residue $\mathbf{N}$, and in the degenerated nerves from the collagen $\mathbf{N}$. Residue $\mathbf{N}$ in degenerated nerve was quite independent of length of $\mathrm{NaOH}$ extraction. In view of the results with degenerated nerves, it is possible that a real loss of collagen $\mathbf{N}$ from undegenerated nerves was entailed by double-length $\mathrm{NaOH}$ extraction, but the amount of loss was obviously quite negligible. With degenerated nerves the loss was appreciable, and necessitated careful standardization of technique when comparisons were intended. In the present work equal numbers of experiments with each extraction period were used at each time of degeneration in order to avoid serious bias.

\section{Expression of Results}

The nerves used were either undegenerated, or degenerated for periods of $25,50,100$, or 200 days.
They will be referred to as 0-day nerves, 25 -day nerves, 50-day nerves, etc. The two nerves from each rabbit, one of which was always 0-day, except in two experiments, where one was.100-day and one 260-day, will be referred to as paired. Considerable changes in wet weight of a given length of sciatic nerve occur during degeneration, as shown in Table I, column 3, where we give the mean percentage which degenerated nerves form of their respective paired 0-day nerves. It is, therefore, not useful for comparative purposes to express collagen content as percentage of wet weight. For that reason we have taken a standardized region of each sciatic nerve and have compared the absolute collagen content of such regions. Simply to do this, however, neglects the variation in size of sciatic nerves from rabbit to rabbit, introducing an unnecessary variability. We have, therefore, adjusted the estimated collagen content of each nerve according to the wet weight of its paired 0-day nerve, or, if it is itself 0-day, according to its own weight. The final value is then the amount which $100 \mathrm{mg}$. of 0-day nerve would contain if appropriately degenerated, the reasonable assumption being made that the paired 0 -day wet weight is approximately that of the degenerated nerve itself before it has been severed. The values tabulated have been obtained in this way. Without this correction foo 0 -day wet weight, the coefficients of variation fo collagen content at different times of degeneration have been found to vary from 16 to 25 , and, with the correction, from 13 to 20 . Another refinement, to which we sometimes refer, calling it the method of pair-differences, is to subtract the 0 -day value for. collagen or other component from the corresponding value of the paired degenerated nerve, and to work directly with differences so obtained. The assumption here is that the collagen or other content of the 0 -day nerve is approximately that of the degenerated nerve before it has been severed. No important gain in uniformity has come from using the pairdifference method, except in the 25-day group, which is discussed below.

All results of micro-Kjeldahl determinations are expressed as mg. of nitroger, referred to as $\mathbf{N}$. By the expression " total $N$ " we mean the sum of collagen $\mathrm{N}, \mathrm{NaOH}$-soluble $\mathrm{N}$ and residue $\mathrm{N}$. This sum must fall slightly short of the true total $\mathrm{N}$, since it excludes the lipin- $\mathrm{N}$ in the fat solvent fraction from stage $(d)$ of the method. Means are given where necessary with standard errors. Tests of significance of difference between means have always been made by $t$ test, the level of significance used for a conclusion that the samples concerned do not come from the same population being a probability (P) that they do so of 0.01 .

\section{Results}

Collagen N.-Mean values, in $\mathrm{mg}$. per $100 \mathrm{mg}$ 0-day wet weight, attained at different times of degeneration, with standard errors, are shown in Table I, column 4, and are also graphed. These $\mathbb{\complement}$ show that a continuous increase in collagen occurs 
Table I.-Wet Weight and Content of Collagen DURING DEGENERATION

\begin{tabular}{|c|c|c|c|c|c|}
\hline 1 & 2 & 3 & 4 & 5 & 6 \\
\hline $\begin{array}{l}\text { Days } \\
\text { of de- } \\
\text { genera- } \\
\text { tion }\end{array}$ & $\begin{array}{c}\text { No. } \\
\text { of } \\
\text { nerves }\end{array}$ & $\begin{array}{c}\text { Wet } \\
\text { weight } \\
\text { as per } \\
\text { cent. of } \\
\text { 0-day }\end{array}$ & $\begin{array}{c}\text { Mg. } \\
\text { collagen } \\
\mathrm{N} \text { per } \\
100 \mathrm{mg} \text {. } \\
0 \text {-day wet } \\
\text { weight }\end{array}$ & $\begin{array}{l}\text { Col- } \\
\text { lagen } \\
\mathrm{N} \text { as } \\
\text { per } \\
\text { cent. } \\
\text { total } \\
\mathrm{N}\end{array}$ & $\begin{array}{c}\text { Collagen } \\
\text { protein } \\
\text { as per } \\
\text { cent. wet } \\
\text { weight }\end{array}$ \\
\hline 0 & 43 & 100 & $0.57=$ & 30 & $3 \cdot 17$ \\
\hline 25 & 12 & $134 \pm 6$ & $0.58 \pm 0.03$ & 27 & $2 \cdot 35 \pm 0 \cdot 10$ \\
\hline 50 & 12 & $129 \pm 4$ & $0.73 \pm 0.04$ & 30 & $3.09 \pm 0 \cdot 10$ \\
\hline 100 & 11 & $112 \pm 3$ & $0.88 \pm 0.04$ & 36 & $4 \cdot 50 \pm 0 \cdot 17$ \\
\hline 200 & 10 & $105 \pm 5$ & $1 \cdot 20 \pm 0.08$ & - & $6 \cdot 2 \pm 0 \cdot 5$ \\
\hline
\end{tabular}

during degeneration, so that by 200 days the content of the nerve has doubled. From 25 days onwards the values at successive times of degeneration are significantly different from each other. The 0-day figure is significantly different from the 50-day figure; but not from the 25-day $(P=0 \cdot 3)$.

Different treatment of the data, using pairdifferences, or confining attention to experiments with either short or long $\mathrm{NaOH}$ extraction, gives

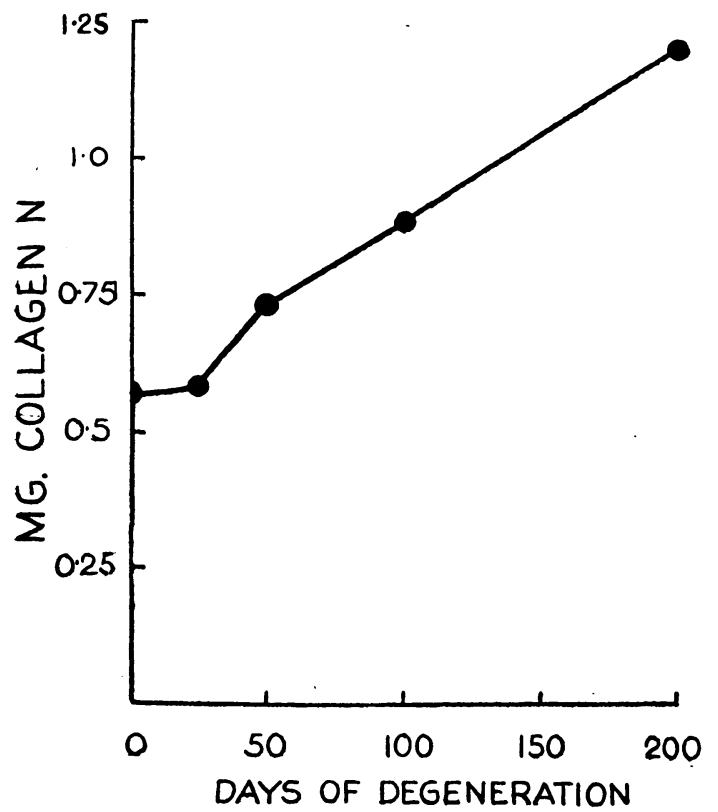

Collagen content, expressed as mg. of collagen $\mathrm{N}$ per $100 \mathrm{mg}$. of the original undegenerated nerve, at successive times of degeneration.

practically identical results, which with one exception we need not quote. We found that the 25-day nerves contained significantly more collagen than their 0-day paired nerves, when we examined pairdifferences in the six experiments with short $\mathrm{NaOH}$ extraction. The mean difference between 0 and 25 days in these experiments was $0.077 \pm 0.014 \mathrm{mg}$. collagen $\mathrm{N}$. We consider, therefore, that collagen is formed during the first 25 days of degeneration but that double-length $\mathrm{NaOH}$ extraction reduces the difference in collagen between 0 and 25 days so much that it ceases to be statistically significant.

These results are expressed in Table II in terms of collagen $\mathrm{N}$ (in $\mu \mathrm{g}$ ) formed per day during successive periods, neglecting the uncertain 25-day value.

TABle II.-COllagen N FORMED IN $\mu$ G. PER DAY, DURING DEGENERATION

\begin{tabular}{c|c|c}
\hline 1 & 2 & 3 \\
\hline $\begin{array}{c}\text { Period of } \\
\text { degeneration } \\
\text { days }\end{array}$ & $\begin{array}{c}\text { Estimated from } \\
\text { mean collagen } \\
\text { contents }\end{array}$ & $\begin{array}{c}\text { Estimated from } \\
\text { pair-differences }\end{array}$ \\
\hline $0-50$ & $3 \cdot 1 \pm 0 \cdot 8$ & $2 \cdot 7 \pm 0 \cdot 5$ \\
\hline $50-100$ & $3 \cdot 0 \pm 1 \cdot 0$ & $3 \cdot 5 \pm 1 \cdot 1$ \\
\hline $100-200$ & $3 \cdot 2 \pm 0.9$ & $2 \cdot 9 \pm 0.9$ \\
\hline
\end{tabular}

Estimates derived both from the means of all nerves at each time of degeneration and from pair-differences are given. These are in good agreement. Collagen appears to be formed at rather a constant rate, which is illustrated by the straightness of the line in the graph. Such estimates of rate are, however, of poor reliability, as their standard errors indicate. We made two paired experiments with nerves of 100 and 260 days. The pair-differences show a rate of formation of collagen $\mathbf{N}$ during this period of 2.7 and $3.1 \mu \mathrm{g}$ per day, which suggests that the rate of approximately $3 \mu \mathrm{g}$ per day is carried on at least this far beyond 200 days. In Table I, column 5 , we show the percentage which the collagen $\mathbf{N}$ forms of the total $\mathrm{N}$ (i.e. collagen $\mathrm{N}+\mathrm{NaOH}$-soluble $\mathrm{N}+$ residue $\mathrm{N}$ ). A rapid increase of $\mathrm{NaOH}$-soluble $\mathrm{N}$ during the first 25 days causes a decline during this period in the proportion of collagen $\mathbf{N}$. After this, collagen $\mathrm{N}$ increases relatively faster than the remaining $\mathrm{N}$. We have no figures for 200 days, but two nerves at 260 days showed 49 and 50 per cent. collagen $\mathbf{N}$.

In Table I, column 6, our results are expressed in the form of mg. of collagen protein as a percentage of the wet weight of the nerve. We have used a conversion factor of 5.58 for estimating collagen protein from collagen $\mathrm{N}$, which seems to be widely accepted (see Eichelberger, Eisele, and Wertler, 1943), but this factor may be too high (the data of Bergmann and Stein, 1939, for instance, indicate a factor of 5.38). The percentage, which in undegenerated nerve is 3.2 per cent. (range 2.0-3.9 per cent.), falls during the first 25 days with the great increase in wet weight, and then rises again as weight decreases and collagen increases.

In order to obtain the maximum material possible in each experiment, we included initially a $2-3 \mathrm{~cm}$. length of the sural branch of the sciatic from the thigh region. This has the disadvantage, however, that we have not investigated the cellular behaviour of the sural as we have that of peroneals and tibials 
(Abercrombie and Johnson, 1942, 1946), and comparisons of collagen formation obtained in the present work with cellular behaviour previously determined may be vitiated. With increasing experience of the technique, we have felt able to estimate the surals separately in a limited number of experiments. Results are shown in Table III. The

Table III.-Wet Weight and Collagen Content of Sural Nerve during Degeneration

\begin{tabular}{c|c|c|c}
\hline 1 & 2 & 3 & 4 \\
\hline $\begin{array}{c}\text { Days of } \\
\text { degeneration }\end{array}$ & $\begin{array}{c}\text { No. of } \\
\text { nerves }\end{array}$ & $\begin{array}{c}\text { Wet } \\
\text { weight } \\
\text { mg. }\end{array}$ & $\begin{array}{c}\text { Mg. collagen } \\
\text { N per 100 mg. } \\
\text { wet weight of } \\
\text { whole 0-day } \\
\text { sciatic }\end{array}$ \\
\hline 0 & 8 & $2 \cdot 5 \pm 0 \cdot 3$ & $0.048 \pm 0.006$ \\
\hline 50 & 6 & $6.0 \pm 0 \cdot 2$ & $0.068 \pm 0.006$ \\
\hline 100 & 4 & $4 \cdot 7 \pm 0 \cdot 2$ & $0.081 \pm 0.006$ \\
\hline
\end{tabular}

values in column 4 are expressed as mg. collagen $\mathrm{N}$ per $100 \mathrm{mg}$. 0-day whole sciatic, so as to be in the same units as the values for the whole nerve given in Table I, column 4. It appears that although the sural increases greatly in wet weight (Table III, column 3), its contribution to the changes in collagen in the whole sciatic is negligibly small. The undegenerated sural apparently contains a dispropor-tionately large amount of collagen $(1.5 \mathrm{mg}$. $\mathrm{N}$ per $100 \mathrm{mg}$. wet weight of 0 -day sural), and during degeneration it adds an unusually large amount of collagen to this $(0.6 \mathrm{mg}$. up to 50 days, $0.9 \mathrm{mg}$. up to 100 days, both referred to $100 \mathrm{mg}$. of 0 -day sural). Difficulties of estimations of all kinds on such minute fragments of nerve make these figures subject to considerable reserve.

Other Nitrogen.-Changes in other nitrogen fractions are shown in Table IV. We have no data

TABle IV.-NON-COLlagen $\mathbf{N}$ AND TOTAL $\mathbf{N}$ DURING DEgENERATION, IN MG. PER 100 MG. O-DAY WET WEIGHT

\begin{tabular}{|c|c|c|c|c|}
\hline 1 & 2 & 3 & 4 & 5 \\
\hline $\begin{array}{l}\text { Days of } \\
\text { degen- } \\
\text { eration }\end{array}$ & $\begin{array}{l}\text { No. of } \\
\text { nerves }\end{array}$ & $\begin{array}{c}\mathrm{NaOH}- \\
\text { soluble } \\
\mathbf{N}\end{array}$ & $\underset{\mathbf{N}}{\text { Residue }}$ & $\underset{\mathbf{N}}{\text { Total }}$ \\
\hline 0 & 33 & $1 \cdot 10 \pm 0.02$ & $0 \cdot 201 \pm 0.009$ & $1.86 \pm 0.02$ \\
\hline 25 & 12 & $1.53 \pm 0.05$ & $0.031 \pm 0.003$ & $2 \cdot 15 \pm 0.07$ \\
\hline 50 & 11 & $1.71 \pm 0.08$ & $0.036 \pm 0.004$ & $2 \cdot 49 \pm 0 \cdot 11$ \\
\hline 100 & 11 & $1.59 \pm 0.05$ & $0.031 \pm 0.002$ & $2.50 \pm 0.06$ \\
\hline
\end{tabular}

for 200-day nerves. The $\mathrm{NaOH}$-soluble $\mathrm{N}$ (column 3 ) is the largest fraction of $N$ in the stages studied, forming 60-70 per cent. of the total N. It increases sharply and significantly during the first 25 days.
After that there are relatively small changes. The 50-day value is a little higher than the 25- and 100-day values, but not significantly so $(P=0.07$ for $25-50$ day difference). Two 260-day nerves show a content approximately that of their 100-day paired nerves. Residue-N (column 4) shows a very large and highly significant fall between 0 and 25 days. It drops from 11 per cent. of total $\mathrm{N}$ to 1.5 per cent. After this it does not change significantly and maintains the same low value at 260 days. Total $N$ (column 5) rises up to 50 days. The change between 0 and 25 days is significant, and so is the change between 25 and 50 days. The 50-day and 100-day values are practically identical. The two nerves at 260 days show, however, a value considerably higher than their paired 100 -day nerves $(0.35$ and $0.40 \mathrm{mg}$. higher, which would be slightly more if it were possible to standardize them for 0 -day wet weight). This suggests that total $\mathbf{N}$ really rises beyond 100 days, though the point is not proved.

The total $\mathrm{N}$ content of the nerve as a percentage of the wet weight decreases from 1.86 to 1.60 per cent. between 0 and 25 days, and then rises to 1.92 per cent. at 50 days and $2 \cdot 24$ per cent. at 100 days, doubtless rising further by 200 days (in the two 260day nerves it is 2.40 per cent.). Most of the increasing concentration of $\mathbf{N}$ after 25 days is due to collagen formation, but the non-collagen $\mathrm{N}$ increases relative to wet weight also. It is 1.30 per cent. at 0 -day, 1.17 per cent. at 25 days, 1.35 per cent. at 50 days and 1.45 per cent at 100 days.

\section{Discussion}

There seems little reason to doubt that, with reservations to be discussed, the method of Lowry, Gilligan, and Katersky (1941) gives an adequate estimate of collagen in the very small quantities of tissue which we have used. We find that collagen is formed in each of the periods of degeneration for which our data provide information, and in quantities such that during the first 200 days of degeneration the collagen content of a nerve approximately doubles.

The reservations as to the accuracy of the method are two. First, doubling the period of $\mathrm{NaOH}$ extraction slightly but significantly diminishes the collagen value in degenerated nerves, though it does not significantly do so in undegenerated nerves. The $\mathrm{NaOH}$-soluble $\mathrm{N}$ correspondingly increases, but the residue $\mathbf{N}$ is not changed. This we interpret as meaning that newly-formed collagen is attacked by $\mathrm{M} / 10 \mathrm{NaOH}$. It might, of course, mean that non-collagen protein is inadequately removed, from degenerated nerves only, by short $\mathrm{NaOH}$ treatment, and that it is then dissolved during autoclaving. But imperfect extraction with $\mathrm{NaOH}$ would probably lead to an increase in residue $\mathrm{N}$, which has not taken place. As a result of this effect, our estimates of collagen in degenerated nerves are probably somewhat too low. Secondly, it is possible that the collagen content is sometimes slightly overestimated owing to extraction of some non-collagen $\mathbf{N}$ during autoclaving. Assuming an error proportional to 
the amount of residue $\mathrm{N}$, the 0-day nerves will clearly be much more affected by this error than the degenerate nerves.

These reservations are only likely to be important when extremely small differences of collagen content are in question, as when comparing 0-day and 25day nerves. The conclusion that some collagen is formed during the first 25 days of degeneration rests in fact on our interpretation of the first reservation, since a significant increase has been demonstrated only by disregarding experiments with double-length $\mathrm{NaOH}$ extraction. We believe this interpretation to be the most probable, and that collagen is, therefore, formed during that period. As to how much collagen is formed during the first 25 days, (an interesting question since this period differs from succeeding ones in that the cell population is increasing by mitosis) we can, in view of the above reservations, say little. But at least this period is not exceptionally active in collagen formation, even allowing for the fact that its cell population averages little more than 0.5 of that between 25 and 50 days, as calculated from the figures for nuclear.population of Abercrombie and Johnson, 1946.

Disregarding the first 25 days, collagen content seems to rise almost linearly. It would, of course, be going much further than our data warrant to suppose that a really linear rise represents the average behaviour of rabbit sciatic nerves. The most reasonable interpretation of our data is that at or soon after the onset of Wallerian degeneration the cells, whether all or some of the cells is not known, are switched into a phase of steady collagen formation, the rate of which does not greatly alter for at least $\mathbf{2 0 0}$ days. Our data, however, certainly do not exclude the possibility that in the later stages of degeneration the rate of formation falls off. Much more extensive experiments than we have done would be needed to get an accurate picture of rate of formation. It is, however, interesting that very long degenerated human nerves become extraordinarily collagenous: an example is described by Young, 1945. This may mean that a high rate of collagen formation is very persistent. It is not possible as yet to compare collagen formation in degenerating nerve with that in any other tissue after injury. The only data we have for other tissues are tensile strength measurements of healing wounds, which do not provide comparable information.

Collagen formation seems to be accompanied by an increase in the total $\mathbf{N}$ content of the nerve, suggesting that collagen formation is not simply a matter of conversion of local $\mathbf{N}$ sources. This increase is clear from our data in the period up to 50 days. The total $\mathrm{N}$ at $\mathbf{1 0 0}$ days is the same as that at 50 days, but this may well be a misleading effect of smaH samples. That the total $\mathbf{N}$ continues to grow beyond 50 days is strongly suggested by two paired experiments, in which 260 -day nerves showed a much higher total $N$ than the 100-day nerves paired with them. It seems likely that after the period of cell proliferation and nerve-fibre destruc- tion, which occupies the first 25 days of degeneration, non-collagen $\mathbf{N}$ does not greatly alter, while collagen $\mathbf{N}$ increases. The nerve, therefore, takes in nitrogen, and in this respect it grows. It loses water at the same time, judging by the wet weights, and consequently the percentage which total $\mathbf{N}$ forms of wet weight increases considerably. The suggested increase of total $\mathrm{N}$ as a consequence of collagen formation requires, however, further investigation.

The nerve-fibre destruction during the first 25 days of Wallerian degeneration is, presumably, reflected in the great drop in amount of residue $\mathbf{N}$. Eleven per cent. of the $\mathbf{N}$ of the undegenerated nerve is residue $\mathbf{N}$, probably largely "neurokeratin". From 25 days onwards, the residue $\mathbf{N}$ lies at a steady value, one-sixth of that of the undegenerated nerve. This very small amount presumably comes from insoluble cell proteins. Evidently the destruction of nerve-fibre proteins is substantially complete by 25 days. Previous work has suggested that the myelin lipins are destroyed in approximately the same period (Noll 1899; Mott and Halliburton, 1901). Nerve-fibre destruction does not, however, entail a loss of total N. Quite the contrary. The loss of residue $\mathbf{N}$ during the first 25 days is more than compensated by the increase in $\mathrm{NaOH}$-soluble $\mathbf{N}$, which presumably comes largely from cell multiplication. The $\mathrm{NaOH}$-soluble $\mathbf{N}$ must, however, have numerous other sources. It no doubt receives contributions from cell-proteins, blood, œdema fluid, intercellular proteins other than collagen, and perhaps from immature collagen. In undegenerated nerve it must partly come from the nerve fibres. An unknown proportion of it is nonprotein nitrogen. In undegenerated nerves some of the $\mathrm{NaOH}$-soluble $\mathrm{N}$ is probably lipin-N. But judging from our estimates of the amount of lipin- $N$ in the fat solvent fraction from stage $(d)$ of the method, taken in conjunction with the known lipin content of nerves, lipin- $\mathrm{N}$ is not more than about one-tenth of $\mathrm{NaOH}$-soluble $\mathrm{N}$. Such lipin-N is sure to decrease as degeneration proceeds. In the circumstances, quantitative changes in $\mathrm{NaOH}$ soluble $\mathrm{N}$ cannot be adequately interpreted.

The conclusion from our work which seems to be relevant to neurosurgery is that the process of collagenization is continuous over a long period of degeneration. It is a reasonable assumption that collagen formation around shrunken Schwann tubes hinders their eventual expansion when reinnervated, and so hinders the return of fairly normal fibre diameters. It is also a reasonable assumption that the process of Wallerian degeneration is substantially similar in man and rabbit. Thus our results suggest that, once the tubes have shrunk, delay in suture means a continuously worsening prospect of adequate expansion of Schwann tubes on reinnervation. It would be unwise to postulate that, after early suture and consequent early reinnervation, collagen formation is suppressed. But in these conditions the new collagen would form pari passu with the expansion 
of the Schwann tubes, and would, therefore, be likely to hinder much less seriously the return to normal fibre diameters.

\section{Summary \\ The . Lowry, Gilligan, and Katersky (1941) method of collagen estimation applied to rabbit sciatic nerve shows that collagen is formed during Wallerian degeneration.}

Undegenerated nerves and nerves degenerated $25,50,100$, and 200 days have been investigated. At each time of degeneration the mean collagen content has been significantly higher than at the preceding time, though the increase during the first 25 days of degeneration is not so well established as are the subsequent increases.

One hundred $\mathrm{mg}$. of undegenerated nerve contains an average of $0.57 \mathrm{mg}$. of collagen $\mathrm{N}$, and in the course of 200 days' degeneration it lays down on the average a further $0.63 \mathrm{mg}$. Our data do not give a reliable picture of the rates of collagen formation during different periods of degeneration; but they suggest that the rate is nearly constant throughout the period studied.

The mean content of collagen protein is 3.2 per cent. of wet weight in undegenerated nerve. At 25 days of degeneration it has fallen to 2.4 per cent., due to an increase in wet weight, but thereafter it rises, reaching 6.2 per cent. in nerves degenerated 200 days.

The destruction of nerve fibres during degeneration entails a large loss of residue $\mathrm{N}$, that is, of protein which is not dissolved by any of the processes of extraction used. The loss is complete by 25 days. The total $\mathrm{N}$ of the nerve, however, increases up to at least 50 days of degeneration.

We should like to thank Mrs. Mary Begg for help in preliminary experiments, and Miss Kathleen Rice for technical assistance throughout. The expenses of this investigation were partly met by a grant from the Medical Research Council.

\section{REFERENCES}

Abercrombie, M., and Johnson, M. L. (1942). J. exp. Biol., 19, 226.

- - (1946). J. Anat., Lond., 80, 37.

Bergmann, M., and Stein, W. H. (1939). J. biol. Chem., 128, 217.

Eichelberger, L., Eisele, C. W., and Wertler, D. (1943) Ibid., 151, 177.

Holmes, W., and Young, J. Z. (1942). J. Anat., Lond., 77,63 .

Lowry, R. H., Gilligan, D. R., and Katersky, E. M. (1941). J. biol. Chem., 139, 795.

Mott, F. W., and Halliburton, W. D. (1901). Philos. Trans. B., 194, 437.

Noll, A. (1899). Hoppe-Seyl. Z., 27, 370.

Sanders, F. K., and Young, J. Z. (1944). J. Physiol $103,119$.

Young, J. Z. (1945). Edinb. med. J., 52, 262. 